\title{
Transportation Fuel from Algae
}

\author{
Kailin Wang \\ North China Electric Power University,Changping District,Beijing, China \\ wangkailin0728@163.com
}

Keywords: Algae; Biofuel; Transportation fuel; Biodiesel; Hydrogen

\begin{abstract}
Algae biofuel has been recently seen as a very promising renewable energy sources to replace the gasoline as the transportation fuel. Federal government has planned to replace $30 \%$ of fossil fuels consumption in transportation sector with algae biofuel by 2020 , and completely taking over conventional fuels by 2030 . Behind the reasons why the algae was viewed so high are several tempting features made this microorganism an ideal future fuel source. The most important two are: 1) the astounding high energy production--up to 833 times of corn produced per year. 2) the low requirements for raw material and environment-- sewage or saline water is viable for cultivation. However, nowadays algae industry is still harassed by a serious technical problems-- contamination, which accounts for why this hopeful enterprise progressed so slowly.

This paper include discussions about advantages of algae, availability, products, sustainability and economical feasibility.
\end{abstract}

\section{Introduction}

As we know, 200 years ago, the world experienced an energy revolution which launched the Industrial Age. With the advent of the Industrial Revolution, the use of energy in the form of fossil fuels began. And people became more and more relying on fossil fuels, which leads to billions of carbon emissions released into the atmosphere. Large fraction of greenhouse gas emissions come from human activities. Transportation fuel exhaust and electricity production are two major sources of energy related $\mathrm{CO}_{2}$ emissions in most countries ${ }^{[\mathrm{i}]}$. The transportation sector takes up around $20 \%$ of the global energy consumption and is the biggest consumer of oil in the world ${ }^{[i i]}$. As a result of that, there has been increasing attention to renewable sources. And it seems to be an effective solution to replace fossil fuels with biofuel.

Biofuel are broken down into several generations:

First-generation Biofuel. First generation biofuel is also called conventional biofuel. They derived directly from feedstocks like rapeseed, corn, sugarcane and sugar beet, which are also can be consumed as human food. So it's a contentious issue that choosing fuel or food. Apart from these, the first generation biofuel also suffer from a number of constraints on food security, higher food prices, carbon emissions increase, land use and water-related issues ${ }^{[i i i]}$.

Second-generation Biofuel. Due to the limitations of the first generation biofuel, more and more countries have begun to pay close attention to second generation biofuel which are based on non-edible raw materials. Compared with the first generation of biofuel, the second generation biofuel is more sustainable and has a lower impact on food production. The feedstocks include agricultural wastes, woody crops and specific biomass crops. This will undoubtedly greatly improve the efficiency of biomass utilization, thereby promoting the development of the second generation biofuel.

Lignocellulose, as renewable biomass, could be used as raw materials to produce ethanol by enzymolysis. It has a extremely impressive application. In the United States, for example, the US Congress has approved a series of agricultural bills to encourage the use of bioethanol in nearly a decade. And the US Department of Energy has released a detailed biofuel development roadmap aimed at achieving the commercial production of cellulosic ethanol ${ }^{[\mathrm{iv}]}$.

Third-generation Biofuel. Although the second generation biofuel has overcome the problem of food security, the defect in land use becomes the bottleneck in scale production of biofuel. Therefore, researchers are gradually turning their attention to microorganism as an raw material. In 
recent years, the third generation biofuel, such as algae, has become a promising alternative source of energy ${ }^{\mathrm{v}}$. Compared with first and second generation biofuel, third generation biofuel has many advantages:

Do not use land suitable for other types of agriculture. Algae can be grown almost anywhere like salt water, wasted water and produced water, which reduces the competition with agricultural crops.

Capable of higher yield with lower resource input. Algae can produce 50 to 100 times as much oil per hectare per annum compared to oilseed rape.

High photosynthetic efficiency. Due to the high high conversion efficiency, algae has a short growth period.

Can recycle and fix $\mathrm{CO} 2 . \mathrm{CO} 2$ produced from power station and industrial plants can be used to feed process.

However, the algae also suffer some disadvantages:

Some researchers genetic engineering to develop optimal algae strains.

Need to be grown under controlled temperature conditions.

Relatively high upfront capital costs. ${ }^{\mathrm{vi}}$

Compared with fossil fuels and first and second generation biofuel, algae as feedstocks to produce biofuel has bright prospective of development. Algae biofuel is likely to become one of the most important renewable energy sources in the future.

\section{Principle}

The entire procedure algae producing fuel is shown like Fig 1. There are four steps. First, select the specific type of algae. Second, put nutrients, $\mathrm{CO}_{2}$ and sunlight into the cultivation ponds. Then within a few hours it is ready to harvest the algae community. One essential part ensuing harvesting is extraction, which is a technologically complex process because some new methods have to be implemented and a large amount of energy is inevitably consumed. The final step is processing, which means converting the dry mass got from the extraction to the biodiesel or other desired products. Looking from the Fig 1., the whole procedure is sustainable because on the one hand some $\mathrm{CO}_{2}$ is consumed as raw material, on the other hand the energy yielded can be recasted into the procedure.

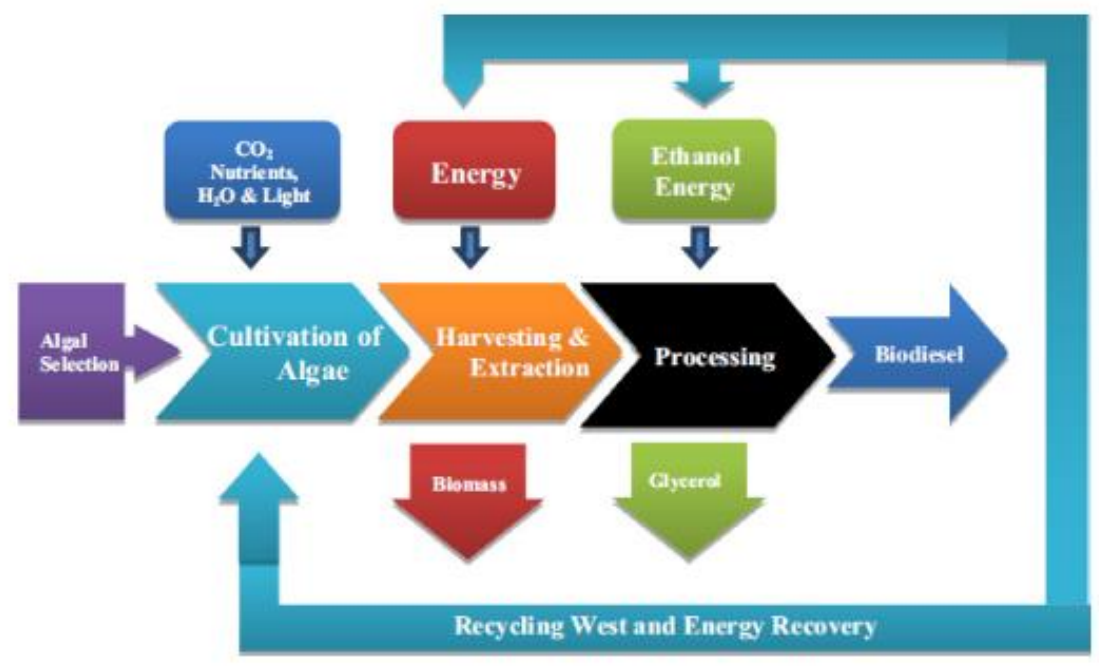

Figure 1. Diagram of the entire procedure ${ }^{[\mathrm{vii}]}$ 


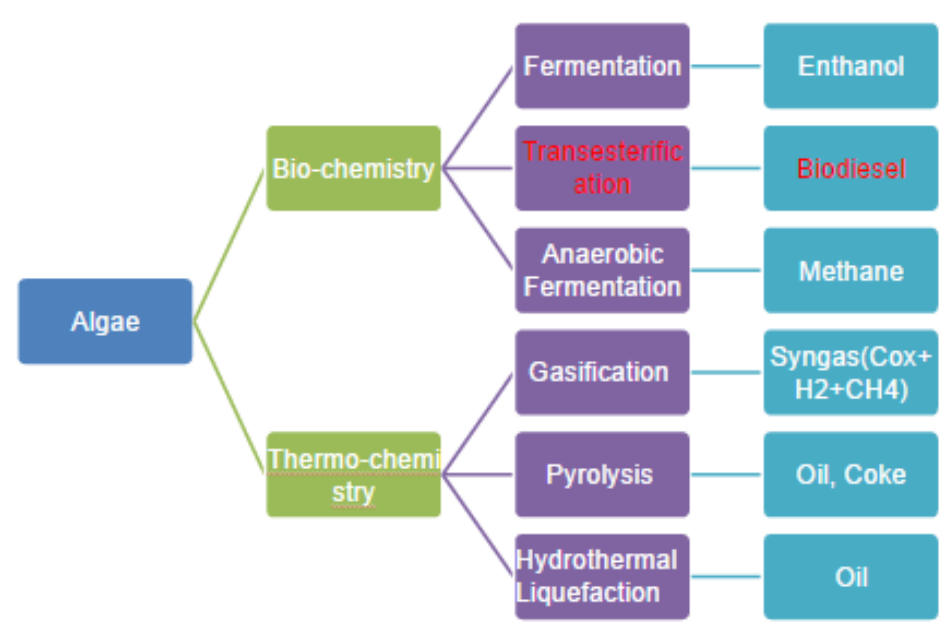

Figure 2. Diagram of products and methods

\section{Availability}

Some sorts of limitation do exist due to the currently immature technologies. There are roughly two limitation factors.

\section{Land}

Obviously, the land must be flat (no more than 5 degrees slope) and relatively large scale and located at moderate altitude. If the altitude is not suitable, the algae will not grow fast. So we must choose the right place to cultivate the algae.

\section{Climate}

You need somewhere with sufficient water resources, sufficient sunlight and moderate temperature, most importantly, some level of $\mathrm{CO}_{2}$. Like the under table, produce per kilogram dry biomass algae, we need put in 2 kilogram $\mathrm{CO}_{2}$. They are the necessary to algae growth. If the climate is too bad, the algae will not grow up.

Although, there are two limitation for algae, it also have some advantages. Comparing to the other fuel plants like corn or soybeans, algae is quite easy to achieve. Like the table shows, the algae can produce 12,000 liters biodiesel per hectare per year. And if we want to produce global oil demand, the algae will only take $2.7 \%$ of global land mass. Comparing to the soybean, it is 60 times. $^{[5]}$

\section{Products}

The production of algae is also important. There are four kinds of products:

\section{Hydrogen.}

There are two ways to make the hydrogen. One is biochemical processes, the other is gasification of algae biomass. In our life, there are two ways to use hydrogen in transportation. One is hydrogen make electric power, than vehicles and trains use electric power. It is the indirect way to use hydrogen. The second is used in the hydrogen cars. The Tokyo hydrogen car (MIRAI) is easy to buy.

\section{Biodiesel}

It is well known among these products. And it came into our life for long time. Biodiesel can be used in the diesel engine and with no modifications. And the biodiesel has low flash point, so it will be safe during the transportation. Although, the energy density of biodiesel is a little less than normal diesel, the customer should not worry about it. Because the power of engine using B100 biodiesel will just output 9\% less than using normal diesel. And the biodiesel will harm rubber hoses and clog fuel filter, but these is only a little high cost to customer. In the future, it can replace diesel.

\section{Biobutanol}

It has an energy density similar to gasoline and it also can be used in gasoline engine with no modifications. Compared with E85, it is a better fuel for gasoline engine. 


\section{Jet fuel}

The continental airlines ran the first test using 50/50 biofuel and aircraft fuel on January 82009 . The test showed that no modification to engine was required. And the biofuel from algae has low freezing point issues that have been problematic for other biofuel.

Now, let's draw a temporary conclusion for availability. First, it is theoretically infinite but nowadays practically limited, which means it can increase with the technical development. The main problems restrict is scale-up difficulties and contamination from weeds, microbes or other undesired algae species[ ]. Therefore, an exact calculation for availability is quite difficult. But according to the rough extrapolation, because of the high energy density and high production of algae, it is undoubtedly can take on the whole transportation consumption of US smoothly before the end of fossil fuel.

\section{Sustainability}

The sustainability has two parts. One is resource, the algae grow up fast and can take on the whole transportation consumption. And the second part is about environment. We know the fuel burned will release $\mathrm{CO} 2$. But when the algae grow, it will absorb CO2. So the biofuel will not discharge much $\mathrm{CO} 2$. The second problem is water. Other plants using for biofuel need fresh water. But algae can use waste water to cultivate. Compare with normal diesel, the biodiesel has lower sulfur oxide emissions and lower volatile organic compounds. And it discharge more NOx, but not too much, so we shouldn't worry about that. So the algae biofuel is sustainable.

\section{Economical Feasibility}

The cultivation of algae biomass for use as a biofuel is costly process. However, the process of refining algae biomass into biodiesel is relatively cheap. The main pitfall to the large-scale commercial production of algae for use as a biofuel seems to be the cultivation of the algae itself. The cost of biomass makes up over $80 \%$ of the cost of production of oil from microalgae ${ }^{\text {viii }}$. One redeeming quality about algae biofuel is that there are plenty of opportunities to recover the cost of algae production, which greatly decreases the price of algae fuel, while providing the consumer with many useful products, some of which would have otherwise come from fossil fuel production.

The unreliability of the open pond process tends to make production of algae species with high oil yields very difficult. This means that less of the algae biomass that is processed consists of the oil necessary to produce biodiesel. However, using the photo bioreactor method is very costly to operate. While the quality of the algae produced is much higher, with oil yields reaching up to $70 \%$, the algae must be kept in very exact conditions and must be constantly tended to ${ }^{[i x]}$. This increases the cost of operation for the photo bioreactors, since they require electricity to run pumps for various nutrient, $\mathrm{CO} 2$ and water supply, as well as instrumentation for the monitoring of these things. These higher operating costs tend to offset the financial gains achieved by cultivating the higher quality algae.

The costs associated with algae fuel production could be greatly reduced if production could be greatly increased. The price of algae fuel is very high because the quantity of algae fuel supplied cannot meet the quantity of algae fuel demanded. This creates a shortage, which drives prices up. This could be addressed simply by increasing the amount of algae cultivated in a year, but there is no respectable infrastructure that currently exists to support this demand. Since the process of creating biofuel from algae is a fairly new technology, large scale production facilities do not exist at this point. However, this can be slowly fixed over time by building more cultivation area.

Production costs can be greatly reduced by selling the dry algal biomass which remains after oil extraction, for use in various other products. Some of these products are animal feeds, nutritional supply, and cosmetics. The dry algal biomass can also be used in digesters to produce methane gas, which can be burned in a gas turbine for electrical power ${ }^{[\mathrm{x}]}$. The process of producing algae biodiesel also presents several opportunities for reusing the materials that go into biodiesel production. For example, the hexane that is used as a solvent to extract the algal oil can be captured 
and reused for multiple production runs.

\section{Conclusion}

For the general discussion part, we drew a few conclusions. The algae has enormous advantages comparing to the old biofuel, for instances, it can endure the harsh environment of sewages and only requires sunlight and $\mathrm{CO} 2$ for supply, and bears extraordinary high productivity far more than the obsolete 2 types of biofuel. The entire procedure from algae to fuels can be divided into four steps: selection, cultivation, harvesting ensued extraction, and processing. After going through the procedure, we could get hydrogen, biodiesel, biobutanol, even jet fuels. And availability as well as sustainability seems rather optimistic though there are minor limitations. Finally the some basic financial questions are answered.

\section{References}

[1] M.Delucchi, Institute of Transportation Studies paper number UCD-ITS-RR-(1997), 97-05.

[2] International Energy Agency. 2014 Key World Energy Statistics. Retrieved from http://www.iea.org/publications/freepublications/publication/keyworld2014.pdf.

[3] Naik S.N., Goud V.V., Rout A.K. Production of first and second generation biofuels: a comprehensive review[J]. Renew Sustain. Energy Rev.,2010,14(2): 578-597.

[4] NAIR P.Adrances in Pyrolysis Technology Enable 2nd Generation Feedstock Applications for Renewable Power, Heat \& Transport Fuels[C]//NPRA Annual Meeting, March 21-23, 2010, Phoenix AZ, USA.

[5] Wikipedia, "Algae Fuel” Wikipedia, The On-Line Encyclopedia

[6] Overview and development perspectives." Progress in Natural Science: Materials International 24.4 (2014): 329-339.

[7] K.Ullah et al./Progress in Natural Science: Materials International 24 (2014) 329-339

[8] Gao, Yihe, Chapin Gregor, Yuanjie Liang, Dawei Tang, and Caitlin Tweed. "Algae Biodiesel a Feasibility Report." Chemistry Central Journal. BioMed Central, 2012. Web. 08 Dec. 2016.

[9] Gardner JG, et al. J Biomech 38, 1861-1868, 2004.

[10]Benemann, J., and Oswald, 1996, Systems and Economic analysis of microalgae. Report to DOENETL. 